XIII.-On the Composition and Analysis of Black Ash or Ball Soda.

$$
\text { By Josiah W. Kynaston, }
$$

FTUDENT, IN THE LIVERPOOL COLLEGE OF CHEMISTRY.

THE immense importance and extent of the soda manufacture will, it is hoped, be considered a sufficient reason for the publication of the following remarks on the composition of one of the intermediate products. The process of Leblanc, although so extensively and so successfully pursued is, nevertheless, as to several of the products of decomposition, not even now, after the lapse of nearly sixty years, thoroughly understood. 
Having, at the suggestion of Dr. Muspratt, undertaken an investigation of the whole process, so as if possible to lead to improved modes of manufacture, it appeared of the utmost importance to ascertain with accuracy, the exact composition of black ash or crude carbonate of soda. Several analyses of this highly complex mixture have appeared from time to time, among which may be mentioned those of Richardson, Unger, Brown, Danson, and more recently that of Samuelson, late of this college.

The most striking discrepancy in the several analyses, is in the composition assigned to the insoluble calcium compound. The exact constitution of this, has also been a question to which several distinguished chemists have devoted much attention, and on which scarcely two have agreed. Thus, Dumas assumes it to be a combination of two equivalents of sulphide of calcium with one equivalent of lime $2 \mathrm{CaS}+\mathrm{CaO}$. Unger, reviewing Dumas' theory of the process of its formation, considers it much more probable that it is a compound of three equivalents of sulphide of calcium, with one equivalent of lime $3 \mathrm{CaS}+\mathrm{CaO}$, a formula also assigned to it by Payen, and adopted by the above mentioned analysts; while Rose regarded it as composed of one equivalent of sulphide of calcium, with one of hydrate of lime $\mathrm{CaS}+\mathrm{CaO}, \mathrm{HO}$. My analysis appears to me to prove decisively that no such salt as any of the above has any existence in fact; and certainly that the insolubility of the calcareous compound cannot be attributed to its being contained in the ash in such a state of combination.

Before stating the reasons for arriving at such a conclusion, opposed as it is to the opinions of such eminent chemists, I will give the method pursued for the determination of the several ingredients, and the calculations founded thereon. The ash examined was kindly supplied to me by Mr. Edmund Knowles Muspratt, and was produced under his superintendence, at the Liverpool Vauxhall Alkali Works. I would here express my acknowledgments to this gentleman for his kindness in explaining to me anything connected with the execution of the process of manufacture. The methods of Brown were adopted in those cases, where they yield accurate results, but in many instances, they were proved to be quite erroneous.

To estimate the relative proportions of the soluble and insoluble salts, a portion of the ash was digested for some time in cold water, afterwards thrown on a weighed filter, and washed. The results can only be considered as approximate, as by continued affusion, 
after the extraction of the salts of soda, the filtrate still continues alkaline. This alkalinity is owing to the presence of caustic lime, produced by the decomposition of the sulphide of calcium, which, by exposure to the air, is gradually decomposed into sulphide and bisulphide of calcium, and caustic lime $3 \mathrm{CaS}+\mathrm{O}=\mathrm{CaS}+\mathrm{CaS}_{2}$ $+\mathrm{CaO}$. If the washing with exposure be still further continued, the sulphur becomes oxidised, giving rise to sulphite and hyposulphite of lime, and lastly to sulphate of lime, all of which pass through the filter. In the estimation, the washing was discontinued on the first appearance of lime in the filtrate. The residue dried at $212^{\circ}$ gave 59 per cent. as the amount of insoluble matter, and consequently 41 per cent. of soluble salts.

To determine the respective quantities of lime and soda, 1.954 grammes were taken, and treated with hydrochloric acid. The filtrate was neutralized with ammonia and again filtered. From this solution, the lime was thrown down by oxalate of ammonia, and the oxalate of lime collected, washed, dried and ignited, yielded $1.225 \mathrm{CaO}, \mathrm{CO}_{2}=35 \cdot 109$ per cent. $\mathrm{CaO}$. This lime as subsequently calculated, exists in the ash as follows:-

$$
\begin{aligned}
& 22 \cdot 307=15 \cdot 934 \mathrm{Ca} \text { as } \mathrm{CaS} \\
& 1 \cdot 8564 \text { as } \mathrm{CaO}, \mathrm{CO}_{2} \\
& 0 \cdot 2344=0 \cdot 1674 \mathrm{Ca} \text { as } \mathrm{CaS}_{2} \\
& 0 \cdot 4245 \text { as } \mathrm{CaO}, \mathrm{S}_{2} \mathrm{O}_{2} \\
& 1 \cdot 0164, \mathrm{CaO}, \mathrm{SO}_{2} \\
& 9 \cdot 2703, \mathrm{CaO}
\end{aligned}
$$

$35 \cdot 1090$

The filtrate from the oxalate of lime was acidulated with hydrochloric acid, and evaporated to dryness, to remove silica. The chloride of sodium was converted into sulphate, and the weight of the latter was $1.075=24.024$ per cent. $\mathrm{NaO}$ contained in the ash as follows:-

$$
\begin{aligned}
& 21 \cdot 5705 \text { as } \mathrm{NaO}, \mathrm{CO}_{2} \\
& 1 \cdot 348=\cdot 0994, \mathrm{Na} \text { as } \mathrm{NaCl} \\
& 0 \cdot 1726 \text { as } \mathrm{NaO}, \mathrm{SO}_{3} \\
& 0 \cdot 6734, \mathrm{NaO}, \mathrm{SiO}_{2} \\
& 0 \cdot 2595, \mathrm{NaO}, \mathrm{Al}_{2} \mathrm{O}_{3}
\end{aligned}
$$


The centesimal amount of soda, as carbonate, silicate, and aluminate was also estimated volumetrically by means of a test acid. It yielded 22.5 per cent.

Another larger portion of the ash, 6.562 grammes, was taken, and in this quantity were determined the ultramarine, silica, charcoal, protoxide of iron (as $\mathrm{FeS}$ ), alumina (as $\mathrm{NaO}, \mathrm{Al}_{2} \mathrm{O}_{3}$ ), and magnesia. This was digested with successive portions of warm water, until the soluble portion was completely extracted. The dark green aqueous solution was boiled until the ultramarine had deposited. This was filtered off, washed, dried, and ignited, and gave 0.9589 per cent.

The filtrate from the ultramarine was acidulated with hydrochloric acid, and boiled, then neutralized with ammonia. The precipitate of alumina thus obtained gave 0.4291 per cent. The filtrate from the last precipitate was again acidulated with hydrochloric acid, and evaporated to dryness, and the residue treated with water, left silica amounting to 0.5086 per cent.

The portion of ash insoluble in water was then treated with very dilute hydrochloric acid, and after expulsion of sulphide of hydrogen, thrown on a weighed filter. From the filtrate, oxide of iron, alumina, and phosphate of lime were thrown down by ammonia. In this precipitate, the iron was estimated by means of permanganate of potassa, and yielded 0.3372 per cent. of $\mathrm{Fe}_{2} \mathrm{O}_{3}$.

After having removed lime from the filtrate, by means of oxalate of ammonia, the magnesia was precipitated by phosphate of soda, and afforded 0.2537 per cent. of $\mathrm{MgO}$.

The residue, undissolved by hydrochloric acid, was dried at $212^{\circ}$ and the weight noted. From this, the charcoal was removed by long continued ignition, and calculated from the loss of weight sustained. It gave 7.007 per cent.

In another portion of ash, 5.543 grammes, the sand, and total amount of sesquioxide of iron, alumina, and phosphate of lime were determined. In this case, the ash was treated with dilute hydrochloric acid, and after expelling sulphide of hydrogen, the liquid was decanted. The residue was then boiled with aqua regia until only the sand remained. The latter dried, ignited, and weighed, gave 0.901 per cent. The two acid solutions were then mixed, and precipitated by ammonia. From the precipitate redissolved in hydrochloric acid, the alumina was removed by excess of potassa. The precipitate of sesquioxide of iron and phosphate of lime thus obtained, gave 2.9952 per cent. From this is subtracted the sesquioxide of 
iron, obtained by solution of the ash in dilute acid, and which is assumed to exist as $\mathrm{FeS}$; the residue $2 \cdot 658$ expresses the quantity of anhydrous sesquioxide of iron and phosphate of lime.

The alumina was thrown down from the potassa solution by ammonia, after treating with hydrochloric acid and chlorate of potassa. The percentage was $1 \cdot 5609$. Subtracting from this, the alumina existing as $\mathrm{NaO}, \mathrm{Al}_{2} \mathrm{O}_{3}$ which is soluble in water, the residue gives $1 \cdot 1318$ as the proportion of anhydrous alumina.

In another portion of ash, 21.4 grammes, sulphuric acid was estimated after treating with hydrochloric acid, by precipitation as sulphate of baryta, and gave $0 \cdot 2228$ per cent. $\mathrm{SO}_{3}$.

The total amount of sulphur was determined by fusing $2 \cdot 131$ grammes of ash with three or four times its weight of nitrate of potassa, treating the fused mass with dilute acid and water, and precipitating sulphuric acid from the filtrate by chloride of barium. The total percentage of sulphur was 14.565 .

The amount of sulphur existing in the insoluble state was also determined in the same manner as the preceding, the soluble portion having been previously extracted by repeated washing. $1 \cdot 546$ grammes were taken, and yielded $12 \cdot 882$ per cent.

The process adopted for the estimation of sulphur as soluble bisulphide, hyposulphite, and sulphite was founded upon the following reactions. Carbonate of cadmium is decomposed by a solution of alkaline sulphide, yielding sulphide of cadmium and carbonate of the alkali. Nitrate of silver, mixed with solution of hyposulphite of soda, affords hyposulphite of silver. When heated in water, the latter is decomposed into sulphide of silver and sulphuric acid, $\mathrm{AgO}, \mathrm{S}_{2} \mathrm{O}_{2}=\mathrm{AgS}+\mathrm{SO}_{3}$.

The same salt added to a soluble sulphite gives sulphite of silver; and this also on heating with water is decomposed, yielding sulphuric acid and metallic silver $\mathrm{AgO}, \mathrm{SO}_{2}=\mathrm{SO}_{3}+\mathrm{Ag}$.

In the two latter decompositions, it will be observed that a quantity of sulphuric acid is produced, one equivalent of which is equal to one either of sulphite or hyposulphite.

The analysis was conducted as follows :- 3.463 grammes of ash were exhausted with cold water. To the filtrate, a quantity of freshly prepared and still moist carbonate of cadmium was added, and the mixture was digested, with frequent agitation, till the alkaline sulphide was decomposed. The precipitate of sulphide and carbonate of cadmium was then filtered off, and treated with dilute acetic acid to remove undecomposed carbonate; the residual 
sulphide was oxidized by fuming nitric acid, water added, and the sulphuric acid produced was then estimated as sulphate of baryta ; calculated as sulphur, it gave 0.2679 per cent.

To the filtrate from the cadmium salts, nitrate of silver was added, and the mixture maintained at a temperature approaching ebullition, until the sulphite and hyposulphite were decomposed, indicated by the successive changes in the colour of the mixture. The precipitate of carbonate, sulphide, and metallic silver was then filtered off, and treated with ammonia to remove the carbonate. The sulphide was then oxidized by fuming nitric acid, and the sulphuric acid precipitated as sulphate of baryta; from the weight of the latter the quantity of hyposulphite was calculated; it gave 0.4852 per cent. of sulphur, existing in this condition.

In the filtrate from the silver precipitate the sulphuric acid was estimated as $\mathrm{BaO}, \mathrm{SO}_{3}$; and deducting that originally existing in the solution, and that formed from the decomposition of hyposulphite, the residue was calculated as sulphurous acid, giving 0.5808 per cent. of sulphur existing in this state.

The several determinations of sulphur, therefore, give the following results :-

Total percentage of sulphur $14 \cdot 565$.

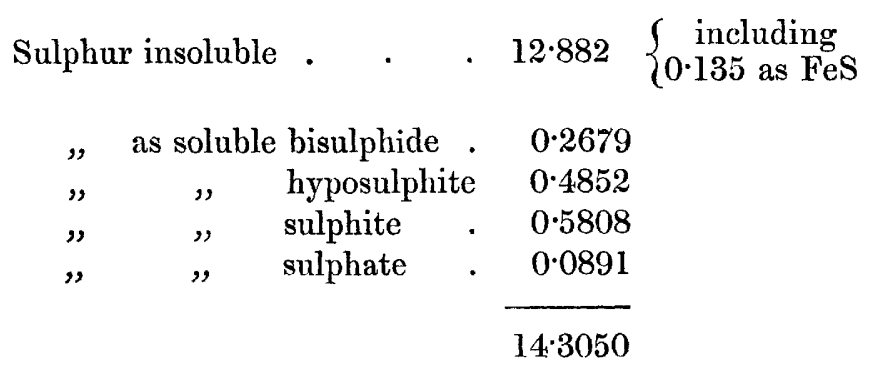

The amount of carbonic acid was arrived at by two distinct operations. 3.531 grammes of ash were digested with successive portions of water, to remove the soluble salts. In this solution, the carbonic acid was estimated by a Fresenius' and Wills' apparatus, with addition of a quantity of neutral chromate of potassa to oxidize the sulphur compounds. It yielded $9 \cdot 6832$ per cent. The residue insoluble in water was transferred to a retort, and treated with hydrochloric acid. The gas evolved was passed into a mixture of chloride of calcium and ammonia. The precipitate 
of carbonate of lime thus obtained, was collected, washed, and introduced also into a Fresenius' and Wills' apparatus, and the carbonic acid liberated by nitric acid. It gave 8.6698 per cent.

The above was found to be the only practicable method for effecting this determination. An attempt was made to estimate this acid at once, in a Frescnius' and Wills' apparatus; but the addition of a large excess of chromate of potassa, and even of permanganate, failed to oxidize the sulphur compounds. Nor could the operation be effected by treating the ash at once with acid, and conducting the evolved gases into a solution of chloride of calcium and ammonia, as the sulphite of lime formed would introduce another error. The sulphur salts existing in the aqueous solution, were readily and completely decomposed by chromate of potassa.

Another process suggested, was to oxidize the sulphite of lime, formed when the evolved mixture of gases was conducted into the chloride of calcium solution, and to deduct the sulphite found from the original weight of the precipitate; but as it was necessary to ascertain exactly the proportion of carbonic acid in the state of carbonate of lime, the process already given was adopted.

Chlorine was estimated by treating $2 \cdot 841$ grammes of ash with nitric acid, expelling sulphide of hydrogen, \&c., and precipitating the filtrate by nitrate silver. It gave 1.533 per cent.

Lastly, the hygroscopic moisture was determined by heating a portion of ash to about $300^{\circ}$. It indicated $0 \cdot 2158$ per cent.

From the above analysis, now given in a tabular form, the percentage composition was calculated.

\begin{tabular}{|c|c|c|c|}
\hline Soluble salts & . $\quad \ldots$ & . & 41 \\
\hline Insoluble matter & and salts & .. & 59 \\
\hline & & & 100 \\
\hline Lime & $35 \cdot 109$ & & \\
\hline Soda & $24 \cdot 024$ & & \\
\hline Ultramarine & 0.9589 & & \\
\hline Silica $\quad \ldots$ & $0 \cdot 5086$ & & \\
\hline Magnesia . & $0 \cdot 2537$ & & \\
\hline Charcoal .. & $7 \cdot 007$ & & \\
\hline Sand & 0.901 & & \\
\hline
\end{tabular}




$$
\begin{aligned}
& \begin{array}{llll}
\text { Alumina } & \ldots & \ldots & 1.5609 \\
\text { Sulphuric acid } & . & 0.2228
\end{array}\left\{\begin{array}{r}
\text { including } 0.4291 \\
\text { as } \mathrm{NaO}, \mathrm{Al}_{2} \mathrm{O}_{3}
\end{array}\right. \\
& \text { Total amount of sulphur } \quad \ldots \quad 14565 \\
& \text { Carbonic acid } \quad \ldots \quad 18.353 \begin{cases}\text { soluble } & 9 \cdot 6832 \\
\text { insoluble } & 8 \cdot 6698\end{cases}
\end{aligned}
$$

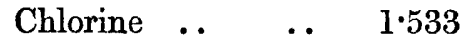

$$
\begin{aligned}
& \begin{array}{llll}
\text { Water } & \text {. } & \text {.. } & 0 \cdot 2158
\end{array}
\end{aligned}
$$

\section{Percentage Composition.}

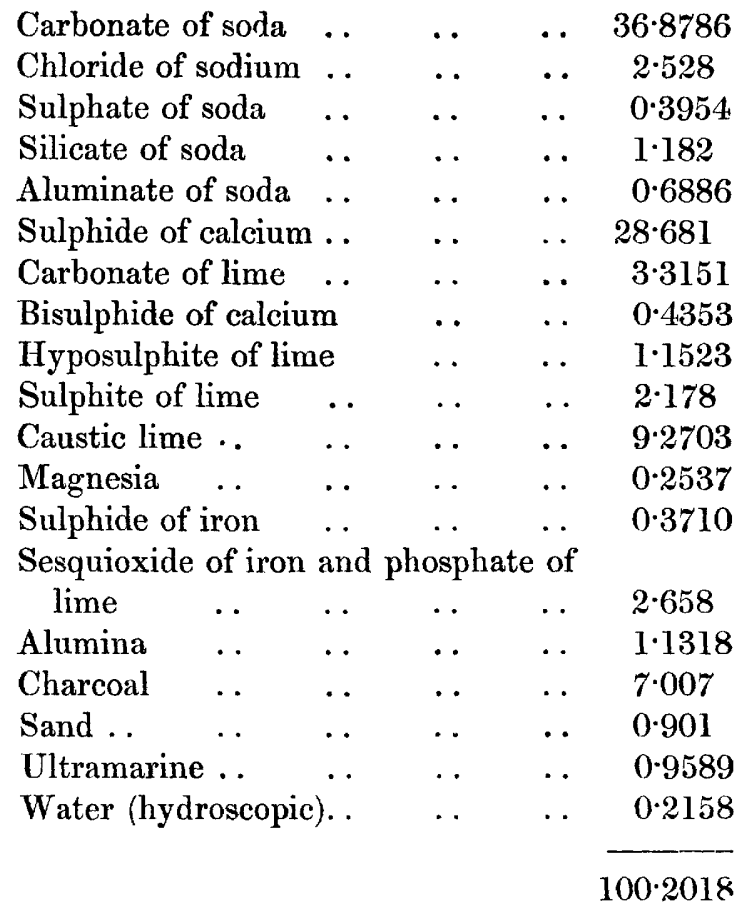

It will be seen in the preceding analysis, that the lime is calculated as existing in several combinations of sulphur, and as carbonate and caustic lime. The reasons for this will be apparent from a study of the analysis. Thus, it will be observed, that in the determination of the carbonic acid, 8.66 per cent. was found to exist in the compound after treatment with water, as carbonate of lime, while $22 \cdot 307$ per cent. $=15 \cdot 93 \mathrm{t}$ of calcium, is shown to 
exist as sulphide of calcium, $\mathrm{CaS}$, the proportion of sulphur remaining insoluble after deducting that combined with iron, as FeS, being the quantity required to produced CaS. Therefore, it is evident, that in the portion of the ash insoluble in waterthat is to say, in soda waste, no lime exists, either combined with $\mathrm{CaS}$, or in the free state.

It must, however, be acknowledged, that this analysis does not disprove the presence of some such compound in the ash, as removed from the furnace, and before treatment with water. But, why assume the existence of such a compound, and what end is to be served? Dumas, when showing the necessity of adding a quantity of lime above that required to produce $\mathrm{CaS}$, says :"But it must yet be observed, that if only two atoms of chalk be used, on dissolving in water, the sulphate of lime converted into sulphide of calcium by the charcoal, will be decomposed by the carbonate of soda, and the result will be the reproduction of the the chalk, together with sulphide of sodium. On this account, three atoms of chalk are used, because, then one atom of lime remains free, and uniting with the two atoms of sulphide of calcium, produces a compound insoluble in cold water. Thus, only the carbonate of soda dissolves, and entirely escapes decomposition by the sulphide produced."

From the above extract, it is evident, that Dumas assumes the existence of his $2 \mathrm{CaS}+\mathrm{CaO}$, because the additional atom of lime has the effect of rendering the CaS insoluble; and this fact is generally adopted by others, as a proof of the existence of this or a similar compound, and certainly the conclusion seems a very plausible one. But if, by treatment with water in contact with the alkaline carbonate, it is found that the lime supposed to be combined with sulphide of calcium is removed from it and converted into carbonate, with simultaneous production of the objectionable compound, then what becomes of the theory, when the very fact that led to its adoption is shown to be erroneous?

Unger, besides the above, reasons from analogy, and considers that because Rose, on leaving a baryta solution for some years in a bottle, obtained a compound, having the formula $3 \mathrm{BaS}+\mathrm{BaO}+28 \mathrm{HO}$, that, therefore, the compound $3 \mathrm{CaS}+\mathrm{CaO}$ might reasonably be supposed to exist. But, what analogy is there between the two compounds? Were the above baryta compound known in the anhydrous condition, $3 \mathrm{BaS}+\mathrm{BaO}$, then we might reasonably assume the existence of the corresponding salt, 
$3 \mathrm{CaS}+\mathrm{CaO}$. But this is unknown, and therefore, the analogy falls to the ground.

But, it will be asked, how then does the additional atom of lime render the CaS so insoluble? I must confess, I am not quite prepared with an answer to this question; but would say in reply, is it not as rational to suppose that an atom of carbonate of lime may unite with the $\mathrm{CaS}$, to produce a difficultly soluble compound $2 \mathrm{CaS}+\mathrm{CaO}, \mathrm{CO}_{2}$ ? If we adopt this opinion, and suppose that combination immediately ensues on treating the ash with water, all difficulty is at once removed.

In the examination of another sample of ash, the annexed results were obtained :-

Carbonic acid as carbonate of lime 8.993 per cent.

Total quantity of lime .. . . 35.348 ",

Sulphur in the insoluble state .. $12 \cdot 768$ ",

These determinations give the following results :-

$$
\begin{aligned}
& \text { Lime }=15.96 \text { calcium as sulphide } 22 \cdot 34=28 \cdot 728 \mathrm{CaS} \\
& \text { " as carbonate of lime. . } \quad .11 \cdot 445=20 \cdot 438 \mathrm{CaO} \mathrm{CO}_{2} \\
& \text { ", , caustic .. } \quad \text {. } \quad \text {. } 1.659
\end{aligned}
$$

The above, although a small quantity of lime remains free, is another proof of the non-existence of any of the hitherto assumed compounds, but is not inconsistent with the theory broached above, the quantity of $\mathrm{CaS}$ there given, requiring 19.95 $\mathrm{CaO}, \mathrm{CO}_{2}$ to form $2 \mathrm{CaS}+\mathrm{CaO}, \mathrm{CO}_{2}$.

Another explanation of the fact, why the additional quantity of lime should prevent the solution of the sulphide, is by supposing that the excess of lime prevents the formation of bisulphide, as, in my opinion, only the bisulphide, and not protosulphide of calcium, is decomposed by the solution of alkaline carbonate. If the supposed compounds of Dumas and Unger are more stable than sulphide of calcium, why are they so readily decomposed by exposure to the air, as is shown in the decomposition proved to take place in the extraction of the solnble salts, and how is it that the products of this metamorphosis are precisely those which occur in CaS under similar circumstances?

By Unger and others, a large quantity of hydrate of soda has been found; I believe no caustic soda can possibly be produced, and certainly from Unger's own results, none is proved to exist, although he has calculated it in this condition. It has been 
suggested that $\mathrm{NaO}$ may be produced by the expulsion of carbonic acid from the carbonate of lime, and a subsequent decomposition of the $\mathrm{CaO}$, and sulphide of sodium; $\mathrm{CaO}+\mathrm{NaS}=\mathrm{CaS}+\mathrm{NaO}$. But, according to the theory of Dumas, the sulphate of soda first decomposes with carbonate of lime, forming carbonate of the alkali, and sulphate of lime, and this salt is afterwards reduced to sulphide of calcium by the charcoal. In this case, no sulphide of sodium can have been formed, and as carbonic acid once combined with soda cannot be again removed by simple heating, of course no caustic soda can be produced.

Whether a sulphite and hyposulphite actually exist is a question that hardly admits of proof, though my researches would certainly lead to the conclusion that they do; for, on treating with cold water, the first washings were found to contain sulphide, sulphite, and hyposulphite, though I allow the possibility and even probability of the formation of these, subsequent to the removal of the black ash from the furnace. In the experiment last given, another curious fact was observed, viz. the existence, simultaneously, of sulphurous acid, and sulphide of hydrogen. Sulphurous acid was distinctly perceptible by its pungent and peculiar odour, on adding hydrochloric acid, while lead-paper was blackened by the gas eliminated. Of course the two gases collected would mutually decompose in the subjoined manner:-

$$
\underbrace{2 \mathrm{HS}}_{\text {Sulphide of hydrogen. Sulphurous acid. }}+\underbrace{\mathrm{SO}_{2}}_{\text {Water. }}+\underbrace{2 \mathrm{HO}}_{\text {Sulphur. }}
$$

Many eminent chemists have asserted, that the two gases could not be collaterally evolved; but this, as Dr. Muspratt affirms, is placed beyond a doubt by his own experiments and by mine.

NoTE.--The sample of ball-soda operated upon by the author had probably been exposed for a considerable time to the arr; since it is well known that the lixivium obtained in the ordinary mode of tre iting ball-soda, always $\mathrm{c}$ ntains a considerable proportion of caus ic alkali, the presence of which would probably interfere with the application of the author's new methods of analysis to the determination of the sulphides, hyposulphites, \&c., in such lixivium.--[ED.] 